\title{
AVALIAÇÃO DE FILMES BIODEGRADÁVEIS ELABORADOS À BASE DE ISOLADO PROTEICO DO MÚSCULO DE CASTANHA (Umbrina Canosai)
}

\author{
M. da ROCHA ${ }^{1}$, M.M de SOUZA ${ }^{1}$, J.E. RAFFI ${ }^{1}$, M.A CARDOZO ${ }^{1}$ e C.H PRENTICE ${ }^{1}$. \\ ${ }^{1}$ Universidade Federal de Rio Grande, Escola de Química e Alimentos \\ E-mail para contato: meriportela@yahoo.com.br
}

\begin{abstract}
RESUMO - Os filmes produzidos a partir de proteínas podem ser utilizados, parcialmente, como embalagens para alimentos, contribuindo para a manutenção da qualidade e minimizando os impactos ambientais proporcionados pelos polímeros sintéticos. Os isolados proteicos de pescado estão sendo estudados para o desenvolvimento de filmes biodegradáveis. O objetivo do presente estudo foi desenvolver e avaliar as propriedades físicas e mecânicas de filmes elaborados à base de isolado proteico de músculo castanha (Umbrina canosai) - IPC. Para tanto, foi elaborado o IPC pelo método de variação de $\mathrm{pH}$. Os filmes foram elaborados pela técnica de casting sob condições alcalinas a partir de 2\% de IPC, 30\% de glicerol, 90 ${ }^{\circ} \mathrm{C}$ e desidratação durante $16 \mathrm{~h}$ a $35^{\circ} \mathrm{C}$. Os filmes apresentaram uma resistência a tração de 8,8 $\mathrm{MPa}$, claros $\left(\mathrm{L}^{*}=93,6\right.$ e $\mathrm{b}^{*}=12,3$ ), opacidade de $11,7 \%$, uma elongação de $5 \%$ e espessura de $0,150 \mathrm{~mm}$, sugerindo que uma melhor formulação deve ser elaborada.
\end{abstract}

\section{INTRODUÇÃO}

Devido ao conhecimento sobre os recursos naturais limitados e os impactos ambientais provocados pela utilização de polímeros sintéticos, existe um grande interesse no desenvolvimento de filmes biodegradáveis. Esses filmes podem ser utilizados como uma alternativa de embalagem de alimentos, pois são versáteis, minimizam a perda de umidade, restringem a absorção de oxigênio, melhoraram as propriedades mecânicas, proporcionando proteção física e mecânica do alimento (Falguera et al., 2011; Rocha et al., 2013).

Os filmes são produzidos basicamente a partir de macromoléculas capazes de formar matrizes contínuas e coesas. Dentre os diversos materiais pesquisados para a produção de filmes, as proteínas se destacam dos demais, pois possuem uma estrutura com 20 monômeros diferentes, o que confere uma ampla gama de propriedades funcionais, especialmente um potencial para ligações intermoleculares, essenciais para formação dos filmes. Filmes a base de proteínas podem formar ligações em posições diferentes e oferecem grande potencial para a formação de numerosas ligações (Ou et al., 2005; Rocha et al., 2014).

As proteínas miofibrilares e sarcoplasmáticas do músculo do pescado são largamente utilizadas para a elaboração de filmes biodegradáveis (Zavareze et al., 2012; Rocha et al., 2013; Rocha et al., 
2014). As proteínas miofibrilares são insolúveis em água, mas podem ser extraídas através da variação de pH da solução (Martins et al., 2011). A castanha (Umbrina canosai) ou"pargo branco" como é chamada no Uruguai e na Argentina, é um pescado de baixo valor comercial, que pode ser amplamente explorado no sul do Brasil para o desenvolvimento de produtos com alto valor agregado como os isolados proteicos (Haimovici et al., 2006).

A formação dos filmes envolve uma série de ligações químicas complexas, que são influenciadas por condições experimentais, tais como: tamanho da macromolécula, plastificante, solvente e temperatura utilizada na formação dos filmes (Cho e Rhee, 2004). A adição de agentes plastificantes é essencial na elaboração dos filmes. Eles são pequenas moléculas de baixa volatilidade, que quando adicionados a materiais poliméricos, modificam a estrutura tridimensional, diminuindo as forças de atração intermoleculares o que aumenta o volume livre e consequentemente a mobilidade da cadeia. Como resultado dessas mudanças, em nível de organização molecular, ocorre um aumento da extensibilidade e flexibilidade do filme. Os plastificantes largamente utilizados em alimentos são glicerol e sorbitol (Swain et al., 2004; Vieira et al., 2011). O tratamento térmico modifica a estrutura das proteínas, causando exposições dos grupos $\mathrm{SH}$ e, consequentemente, produz ligações intra e intermoleculares, promovendo a exposição de grupos hidrofóbicos durante a secagem (Pérez-Gago e Krochta, 2001).

O uso de filmes em aplicações alimentares é condicionado por características como custo, disponibilidade, atributos funcionais da macromolécula, propriedades mecânicas (resistência a tração e elongação), propriedades ópticas (cor e opacidade), efeito de barreira contra o fluxo de gases, solubilidade em água e aceitabilidade sensorial dos filmes (Falguera et al., 2011). O objetivo do presente estudo foi desenvolver e caracterizar as propriedades físicas e mecânicas de filmes elaborados à base de isolado proteico de músculo de castanha (Umbrina canosai).

\section{MATERIAL E MÉTODOS}

\subsection{Matéria-prima}

O pescado foi fornecido por uma indústria de pescado, Pescal S/A, localizada na cidade do Rio Grande, RS-Brasil. Logo após a captura, foi higienizado com água clorada a 5ppm, eviscerado e fileteado. Os filés foram armazenados à $-18^{\circ} \mathrm{C}$ no Laboratório de Tecnologia de Alimentos (LTA) da Universidade Federal do Rio Grande (FURG), até processamento e análise.

\subsection{Obtenção do isolado proteico de castanha}

O isolado proteico de castanha (IPC) foi obtido por solubilização alcalina das proteínas e 


\section{9 a 22 de outubro de 2014 \\ Florianópolis/SC}

posterior precipitação isoelétrica segundo metodologia adaptada de Nolsoe e Undeland (2009). Como agente alcalinizante foi utilizado o $\mathrm{NaOH}(1 \mathrm{M})$ e acidificante o $\mathrm{HCl}(1 \mathrm{M})$. O filé de castanha foi homogeneizada em água destilada $(1: 9 \mathrm{p} / \mathrm{v})$, em reator de aço inoxidável acoplado com banho ultratermostático (Quimis, 214 D2, São Paulo) à $4{ }^{\circ} \mathrm{C}$. Após, foi realizada a solubilização alcalina em pH 11,2 à $4^{\circ} \mathrm{C}$ durante 20 min sob agitação constante com agitador eixo-hélice (IKA, RW 20DZM.n, Alemanha). Em seguida, foi realizada a centrifugação a $9000 \mathrm{~g}$ durante $20 \mathrm{~min}$ em centrífuga (Biosystems, MPW 350/350-R, Brasil), para separação em três fases: lipídeos neutros, proteínas solúveis e insolúveis. A fase intermediária, proteínas solúveis, foi submetida a precipitação isoelétrica das proteínas em pH 5,0 à $4{ }^{\circ} \mathrm{C}$ sob agitação constante durante $20 \mathrm{~min}$. Então, foi realizada nova centrifugação a $9000 \mathrm{~g}$ durante 20 min para obtenção das proteínas precipitadas, reservando a fase sólida precipitada que foi liofilizada em liofilizador (Indrel, IULT - 90D, São Paulo). O isolado proteico de castanha foi triturado em moinho de facas (Tecnal, TE-645, Brasil). Então, a granulometria deste foi padronizada para $0,35 \mathrm{~mm}$ empregando peneiras de 42 mesh (Bertel, Caieiras, São Paulo). O isolado proteico foi analisado em triplicata para determinar o conteúdo de proteína, utilizando metodologia da AOAC (2000) e o mesmo apresentou um conteúdo de proteína de 92,1\%. Esse produto foi utilizado como base na elaboração dos filmes proteicos.

\subsection{Elaboração dos filmes biodegradáveis}

Os filmes foram elaborados segundo metodologia descrita por Rocha et al. (2013). A solução filmogênica (FC) foi elaborada através da adição de $2 \%(\mathrm{p} / \mathrm{v})$ de IPC em reator de vidro $(500 \mathrm{~mL})$ acoplado com banho ultratermostático (Quimis, 214 D2, São Paulo, Brasil), em $100 \mathrm{~mL}$ de água destilada e homogeneizados à $500 \mathrm{rpm}$ com agitador de eixo-hélice (IKA, modelo RW 20DZM.n) durante 25 minutos a $25^{\circ} \mathrm{C}$. Em seguida, o pH da solução filmogênica foi ajustado para 11,5 com solução de $\mathrm{NaOH}(1 \mathrm{M})$. Então, foi adicionado $30 \%$ de glicerol (p/v, g de glicerol/ $100 \mathrm{~g}$ de IPC) à SF e homogeneizada em Ultra-turrax (IKA, T25 digital, Werke, Alemanha) a 10.000 rpm durante 20 minutos. A solução foi aquecida $90{ }^{\circ} \mathrm{C}$ durante $30 \mathrm{~min}$, sob agitação de $500 \mathrm{rpm}$, para desnaturar a proteína isolada. A SF obtida foi filtrada através de um filtro de nylon para remoção de alguns constituintes não dissolvidos. Foram adicionadas $25 \mathrm{~mL}$ da solução filmogênica em placas de Petri acrílicas $\left(9 \mathrm{~cm}\right.$ de diâmetro) e logo desidratadas à $35^{\circ} \mathrm{C}$ durante $16 \mathrm{~h}$ em estufa com circulação de ar (FANEM, 520, São Paulo, Brasil). Os filmes foram armazenados durante 48 horas em dessecadores com $40 \%$ de umidade relativa, para posterior avaliação dos mesmos.

\subsection{Caracterização dos filmes}

\subsubsection{Espessura}

A espessura $(\mathrm{mm})$ dos filmes foi mensurada em micrômetro digital (insize, IP54, São Paulo, Brasil), com uma precisão de 0,001 milímetros. Foram realizadas dez medidas aleatórias em torno de 
cada amostra de filme segundo o método descrito por Rocha et al. (2013).

\subsubsection{Propriedades mecânicas}

A resistência à tração $(\mathrm{RT})$ e a elongação até a ruptura $(\mathrm{E})$ dos filmes foram determinadas em triplicata, segundo metodologia da ASTM D-882-91 (1996), em texturômetro TA.XT plus $_{\text {(Stable }}$ Micro Systems). As amostras foram cortadas em forma de retângulos (80 x $25 \mathrm{~mm}$ ) e fixadas em garras com separação de $50 \mathrm{~mm}$ e velocidade de tração de $0,8 \mathrm{~mm} / \mathrm{s}$. A RT foi calculada dividindo-se a máxima força para rompimento do filme pela área de seção transversal do mesmo. A E foi calculada dividindo-se o alongamento na ruptura do filme pelo comprimento inicial da amostra, multiplicando por 100.

\subsubsection{Cor e opacidade}

A cor dos filmes foi expressa pelos parâmetros de cor CIELab ( $\mathrm{L}^{*} \mathrm{e} \mathrm{b}^{*}$ ) utilizando colorímetro (Minolta, CR-400, Osaka, Japão), operando com $\mathrm{D}_{65}$ (luz do dia) segundo Sobral et al. (2001). A opacidade foi determinada segundo metodologia de Sobral (2000), com modificações. Segundo este método, a opacidade é determinada pela relação entre a opacidade do filme sobreposto sobre o padrão preto e sobre o padrão branco.

\section{RESULTADOS E DISCUSSÃO}

\subsection{Caracterização dos filmes}

A Figura 1 apresenta o filme elaborado à base de isolado proteico de castanha. $\mathrm{O}$ filme elaborado foi facilmente manuseável e homogêneo.

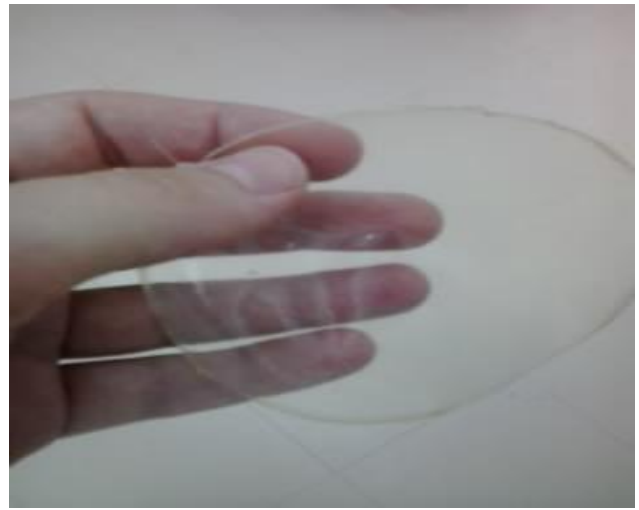

Figura 1. Filme elaborado à base de isolado proteico de castanha (Umbrina canosai) 


\section{9 a 22 de outubro de 2014 \\ Florianópolis/SC}

\subsection{Espessura}

Segundo Akhtar et al. (2010) a espessura é um fator importante para a funcionalidade ideal do filme. Os filmes apresentaram uma espessura média de $0,150 \pm 0,043 \mathrm{~mm}$ superior a encontrada por Tongnuanchan et al. (2011) onde o filme foi elaborado com 2,0\% (p/v) de isolado proteico e $50 \%(\mathrm{~g}$ glicerol $/ 100 \mathrm{~g}$ isolado proteico) apresentou $0,034 \mathrm{~mm}$. Os resultados obtidos sugerem que os filmes elaborados com IPA apresentaram maior espessura devido ao maior conteúdo de sólidos solúveis secos, e o menor conteúdo de glicerol adicionado resultando em menor diluição e maior espessura. Segundo Gounga et al. (2007) filmes preparados com a mesma concentração de isolado proteico, mas com maior conteúdo de plastificante, mostraram diferentes valores de espessura, devido ao acréscimo no conteúdo de sólidos totais do filme.

\subsection{Propriedades mecânicas}

Os filmes deverão ter uma resistência a tração e uma elongação até a ruptuta adequados, pois o mesmo deve manter a integridade constante dos alimentos durante manuseio e armazenamento (Ghasemlou et al., 2011). O filme elaborado com 2\% de IPC e $30 \%$ de glicerol apresentou uma elevada RT de 8,8 \pm 0,4 MPa, quando comparado aos resultados encontrados por Rocha et al. (2013) para filmes elaborados com 3\% de isolado proteico de anchoita (Engraulis anchoita) e 30\% de glicerol (g glicerol/100 g isolado proteico) o qual apresentou uma RT de 1,6 MPa. Segundo PérezGago e Krochta (2001) quando adicionada uma maior concentração de proteína nos filmes, maior será a quantidade de grupos sulfídricos, promovendo um maior número de ligações covalentes $\mathrm{S}-\mathrm{S}$ na matriz filmogênica, e consequentemente formando filmes mais resistentes. Contudo, o presente estudo apresentou uma RT superior quando comparado ao trabalho de Rocha et al. (2013). Esse comportamento pode ser devido a diferença entre as matérias-primas, resultando em um isolado com diferentes composição de aminoácidos.

Segundo Gontard et al. (1994) a resistência à tração dos filmes depende também da natureza do material filmogênico, da coesão da estrutura da matriz polimérica. Os filmes elaborados com IPC apresentaram uma elongação de $5 \pm 0,4 \%$, considerada baixa, quando comparada com os filmes

elaborados por Rocha et al. (2014) o qual apresentou uma elongação de 9,0\% MPa para filmes elaborados com isolado proteico de anchoita.

\subsection{Cor e opacidade}

Alguns autores (Akhtar et al., 2010; Ghasemlou et al., 2011) afirmam que os parâmetros de cor e opacidade são importantes em relação a aparência geral, consumo e aceitação de embalagens para aplicação em alimentos. O filme elaborado com IPC apresentou uma luminosidade (L*) de 93,6 e um valor de $b^{*}$ de 12,3. Isso indica, que esses filmes são claros, como apresenta a Figura 1, e com uma tendência ao amarelo devido ao valor de $b^{*}$. Além disso, os mesmos apresentaram uma opacidade de $11,7 \%$, indicando que esses filmes são opacos. 
Paschoalick et al. (2003), em seus estudos com filmes formulados com $1 \mathrm{~g}$ de isolado proteico de Tilápia do Nilo, observaram uma opacidade variando entre 2 e 7\%, sendo esses filmes menos opacos que os elaborados no presente trabalho. Isto sugere que a concentração maior de isolado, pode ter contribuído para elaboração de filmes mais opacos. A opacidade é desejada para produtos, que a luz seja fator de deterioração, pois em filme opaco não ocorre transmissão de luz (Vicentini, 2003). Segundo Zavareze et al. (2012) A cor e a opacidade do filme dependem da morfologia e da estrutura química relacionada com a massa molar do material e essas características são extremamente importantes em filmes para aplicação em alimentos, em que uma maior transparência é desejável.

\section{Conclusão}

O isolado proteico elaborado a partir do músculo de um pescado com baixo valor agregado, a castanha, pode ser uma fonte alternativa como polímero para a elaboração de filmes homogêneos que possam ser utilizados como embalagem. O filme deverá ser elaborado com outra formulação para melhorar a elongação até a ruptura e a espessura do mesmo. A resistência a tração, opacidade e a coloração apresentaram-se adequados para o uso como embalagem de alimentos.

\section{Referências bibliográficas}

AOAC. Official methods of analysis. (17 th ed.). Maryland, USA: Association of Official Analytical Chemistry, 2000.

Akhtar, M-J.; Jacquot, M.; Jamshidian, M.; Imran, M.; Arab-Tehrany, E.; Desobry, S.Fabrication and physicochemical characterization of HPMC films with commercial plant extract: Influence of light and film composition. Food Hydrocolloids, v.31, p.420-427, 2013.

Cho, S. Y.; Rhee, C.; Mechanical properties and water vapor permeability of edible films made from fractionated soy proteins with ultrafiltration. Lebensmmittel- Wissenschaft Technol., v. 37, p.833-839, 2004.

Falguera, V.; Quintero, J.P.; Jiménez, A.; Muñoz, J.A.; Ibarz, A. Edible films and coatings: Structures, active functions and trends in their use. Trends in Food Sci. \& Technol., v.22, p.292-303, 2011.

Gontard, N.; Duchez, C.; Cuq, J.; Guilbert, S. Edible composite films of wheat gluten and lipids: Water vapor permeability and other physical properties. Int. J. Food Sci. Technol., v. 29, p. 39-50, 1994.

Gounga, M.E.; Xu, S.Y.; Wang, Z. Whey protein isolate-based edible films as affected by protein concentration, glycerol ratio and pullulan addition in film formation. J. of Food Eng., v.83, p.521530, 2007. 


\section{9 a 22 de outubro de 2014 \\ Florianópolis/SC}

Ghasemlou, M.; Khodaiyan, F.; Oromiehie, A. Development and characterisation of a new biodegradable edible film made from kefiran, an exopolysaccharide obtained from kefir grains. Food Chem., v.127, p.1496-1502, 2011.

Haimovici, M.; Absalonsen, L.; Velasco, G.; Miranda, L.V. Diagnóstico do estoque e orientações para o ordenamento da pesca de Umbrina canosai (Berg, 1895). In: Rossi-Wongtschowski, C. L. D. B.; Ávila-da-Silva, A. O.; Cergole, M. C. (Ed.) Análise das Principais Pescarias Comerciais da Região Sudeste-Sul do Brasil: Dinâmica Populacional das Espécies em Explotação - II. São Paulo: USP, p. 77-85, 2006.

Ou, S.; Wang, Y.; Tang, S.; Huang, C.; Jackson, M. G. Role of ferulic acid in preparing edible films from soy protein isolate. J. of Food Eng., v.70, p.205-210, 2014.

Martins, V. G.; Costa, J. A. V.; Damodaran, S.; Prentice, C. Chemical Modification and Structural Analysis of Protein Isolates to Produce Hydrogel using Whitemouth Croaker (Micropogonias furnieri) Wastes. Appl. Bioch. and Biotechnol., v.164, p.819-825, 2011.

Paschoalick, T.M.; Garcia, F.T.; Sobral, P.J. do A.; Habitante, A.M.Q.B. Characterization of some functional properties of edible films based on muscle proteins of Nile Tilapia. Food Hydrocolloids, v.17, p.419-427, 2003.

Pérez-Gago, M. B.; Krochta, J. M. Denaturation time and temperature effects on solubility, tensile properties, and oxygen permeability of whey protein edible films. J. of Food Sci., v.66, p.705-710, 2001.

Rocha, M.; Loiko, M. R.; Gautério, G. V.; Tondo, E. C.; Prentice, C. Influence of heating, protein and glycerol concentrations of film-forming solution on the film properties of Argentine anchovy (Engraulis anchoita) protein isolate. J. of Food Eng., v.116, p.666-673, 2014.

Rocha, M.; Loiko, M. R.; Tondo, E. C.; Prentice, C. Physical, mechanical and antimicrobial properties of Argentine anchovy (Engraulis anchoita) protein films incorporated with organic acids. Food Hydrocolloids, v.37, p.213-220, 2013.

Sobral, P.J. do A. Influência da espessura sobre certas propriedades de biofilmes à base de proteínas miofibrilares. Pesq. Agropecuária Bras., v.35, p.1251-1259, 2000.

Swain, S. N.; Biswal, S. M.; Nanda, P. K.; Nayak, P. L. Biodegradable soy-based plastics: Opportunities and challenges. J. of Pol. Environment, v .12, p.35-42, 2004.

Tongnuanchan, P.; Benjakul, S.; Prodpran, T. Roles of lipid oxidation and $\mathrm{pH}$ on properties and yellow discolouration during storage of film from red tilapia (Oreochromis niloticus) muscle protein. Food Hydrocolloids, v.24, p.426-433, 2011.

Vicentini, N. M. Elaboração e caracterização de filmes comestíveis à base de fécula de mandioca para uso em pós-colheita. 2003. 62f. Tese (Doutorado em Agronomia), Faculdade de Ciências 
Agronômicas, Universidade Estadual Paulista - UNESP, São Paulo

Vieira, M.G.A.; Silva, M.A.; Santos, L.O.; Beppu, M.M. Natural-based plasticizers and biopolymer films: A review. Eur. Polymer J.l, v.47, p.254-263, 2011.

Zavareze, E.R.; Halal, S.L.M.; Telles, Campello, A.; Prentice, C.H. Filmes biodegradáveis à base de proteínas miofibrilares de pescado. Braz. J. Food Technol., v.15, p.53-57, 2012. 